\title{
Investigating the effects of cyclic thermo-mechanical loading on cyclic plastic behaviour of a ninety-degree back-to-back pipe bend system
}

\author{
Nak-Kyun Cho ${ }^{1}$, Haofeng Chen ${ }^{1,2, *}$, Donald Mackenzie ${ }^{1}$, Dario Giugliano ${ }^{1}$ \\ ${ }^{1}$ Department of Mechanical \& Aerospace Engineering, University of Strathclyde, Glasgow, G1 1XJ, United \\ Kingdom \\ ${ }^{2}$ School of Mechanical and Power Engineering, East China University of Science and Technology, 200237, \\ China \\ *Email: haofeng.chen@strath.ac.uk
}

\begin{abstract}
Pipe bends are generally employed for routing piping systems by connecting to straight pipes but backto-back pipe bends are often necessary for confined space applications. In order to achieve safe operation under complex loading, it requires a thorough pipeline integrity assessment to be commenced. This paper investigates the effects of cyclic thermo-mechanical loading on cyclic plastic behaviour of a ninety-degree back-to-back pipe bend system, including temperature-dependent yield stress effects. Structural response interaction boundaries are determined for various different combinations of cyclic and steady loading. Constructed structural responses are verified by full cyclic incremental, step-bystep, Finite Element Analysis. The numerical studies provide a comprehensive description of the cyclic plastic behaviour of the pipe bends, and semi-empirical equations for predicting the elastic shakedown limit boundary are developed to aid pipeline designers in the effective assessment of the integrity of the pipe bends without a requirement for complex Finite Element Analysis.
\end{abstract}

Keywords: Pipe bends, Shakedown, Ratcheting, Cyclic thermo-mechanical load

\section{Introduction}

Power plant piping systems are designed to avoid plastic collapse under monotonic loading and low cycle fatigue and ratcheting failures under cyclic loading. Piping systems are mainly composed of straight pipe and pipe bend components. Pipe bends are generally employed for routing piping systems by connecting to straight pipes but back-to-back pipe bends are often necessary components in confined space applications. Structural integrity assessment of pipe bends is more complex than for a straight pipeline [1-3]. Also, the high temperature operating condition causes the material degradation of the pipe bends, such as the reduction of yield stress under cyclic loading condition, which leads to low cycle fatigue failure or ratcheting failure. It is, therefore, necessary to consider the effects of 
temperature-dependent yield on the pipe bend integrity assessment. Structural integrity assessment under cyclic loadings is an important feature in a wide range of engineering applications and many types of research have reported cyclic plasticity behaviour of engineering problems [4-7].

The full incremental cyclic analysis using the finite element method is commonly employed to determine the cyclic plasticity responses of components subjected to a variety of load combination. However, conventional FEA evaluates the structural response for a specific cyclic loading condition. To construct response boundaries, such as the shakedown and ratchet limits, a significant number of trial loading conditions must be considered. This usually requires an extensive computational resource, in particular for complex three-dimensional geometries. Several Direct Methods have been developed to reduce computational requirements and directly determine the structural response in the form of a Bree diagram [8]. The representative Direct Methods include the Gloss R-Node Method [9], the Elastic Compensation Method (ECM), Dhalla Reduction Procedure [10], and the Linear Matching Method (LMM) [11]. Chen and Ponter extended the scope of the LMM to include ratchet limit analysis, creep rupture limit analysis, and cyclic plasticity analysis which considers creep-fatigue interaction [12, 13], and the whole extended analysis package is called the LMM framework.

The cyclic plasticity of several types of pipe geometry under cyclic loading had been studied before [14-19]. However, no research has been presented for the cyclic plasticity response of the pipe geometry in the subject under thermo-mechanical load with temperature dependent material properties. This paper presents the results of a detailed investigation cyclic plastic behaviour of the pipe bends under cyclic out-of-plane bending and cyclic thermal load with steady internal pressure. Two types of the double pipe bend systems are adopted: the one has two single elbows directly connected to each other and the other one has an additional straight pipe run between the elbows. The former one is the main geometry and the latter is used for parametric studies.

An overview of the LMM framework and its numerical procedures are presented in Section 2. Section 3 provides the problem descriptions which include the finite element model of the pipe bend configuration and the applied loading condition. The numerical results under the cyclic thermomechanical loading are presented in Section 4. Section 5 provides comprehensive parametric studies with geometry effects and variations of loading condition. Finally, Section 6 concludes this paper by summarizing results of this research. 


\section{Numerical Procedures}

\subsection{Overview of LMM}

The LMM is a direct method and numerical procedures for calculating shakedown and ratchet limits. It is a flexible and versatile method with the distinctive features that provide compatible results at each stage of the analysis, incorporates detailed ratchet analysis [20,21] and includes temperature dependent material property effects. The LMM determines non-linear elastic-plastic material response and limit state solutions through a series of linear elastic FEA solutions, in which the local elastic modulus is modified based on the previous solution. Repeating the linear analysis with the updated modulus develops stress redistributions over the structure. This process repeats until the equivalent stress levels match the material yield stress, obtaining accurate load multipliers for upper bound and lower bound to limit load, shakedown, and ratchet limits. The material is assumed to have the elastic perfectly plastic (EPP) and to satisfy plastic incompressibility and the von-Mises yield criterion. The shakedown and the ratchet theorem are summarised briefly in the following two sections.

\subsection{Shakedown theorem}

The shakedown response has constant residual stress $\rho_{i j}^{r}$, which can be described by the range of a load multiplier $\lambda$ which should satisfy $\lambda \leq \lambda_{s}$, where $\lambda_{s}$ denotes the shakedown limit. The LMM calculates both the lower and upper bound limits for the shakedown range.

In the lower bound shakedown theorem of Melan [22], the following condition should be satisfied within the fixed residual stress field $\bar{\rho}$ to keep maintain a state of stress over a structure:

$$
f\left(\lambda_{L B}^{S D} \hat{\sigma}_{i j}+\bar{\rho}_{i j}\right) \leq 0, \text { then } \lambda_{L B}^{S D} \leq \lambda_{s}
$$

where $\lambda_{L B}^{S D}$ is a shakedown lower bound multiplier and $\hat{\sigma}_{i j}$ is an induced elastic solution. This repeats the iterative process until satisfying Eq.(1), calculating the shakedown lower bound multiplier.

The upper bound shakedown theorem of Koiter is that the upper bound multiplier $\lambda_{U B}^{S D}$ should be greater than 1.0 for all kinematically admissible strain rate histories $\left(\Delta \varepsilon_{i j}^{k}=\int_{0}^{\Delta t} \dot{\varepsilon}_{i j}^{k} d t\right) \quad$ over an independent time period $\Delta t$. Hence the following condition should be satisfied: 


$$
\lambda_{U B}^{S D} \iint_{V 0}^{t} \hat{\sigma}_{i j}(x, t) \dot{\varepsilon}_{i j}^{k}(x, t) d t d V=\iint_{V 0}^{t} D\left(\dot{\varepsilon}_{i j}\right) d t d V, \text { then } \lambda_{U B}^{S D} \geq \lambda_{s}
$$

where $V$ is a 3D body of volume and $D$ is a dissipation of energy during plastic deformation.

Considering a structure with surface area $S$, and volume $V$ and an elastic perfectly plastic material satisfying von-Mises yield criterion, part of $S$ is subjected to cyclic loading (mechanical/ thermal ) and constant loading (mechanical/thermal) within $V$ for a cyclic time period $\Delta t$. The remaining part of surface $S$ has zero displacement rates. Based on the upper bound theorem, the admissible strain rate history is associated with a displacement increment field, therefore the shakedown upper bound multiplier can be defined for the combined load history by:

$$
\begin{gathered}
\lambda_{U B}^{S D} \iint_{V 0}^{t} \hat{\sigma}_{i j}(x, t) \dot{\varepsilon}_{i j}^{k}(x, t) d t d V=\iint_{V 0}^{t} \sigma_{i j}^{k} \dot{\varepsilon}_{i j}^{k} d t d V \\
\lambda_{U B}^{S D}=\frac{\int_{0}^{V} \int_{0}^{\Delta t} \sigma_{y} \overline{\dot{\varepsilon}}\left(\dot{\varepsilon}_{i j}^{k}\right) d t d V}{\int_{0}^{V} \int_{0}^{\Delta t}\left(\hat{\sigma}_{i j} \dot{\varepsilon}_{i j}^{k}\right) d t d V}
\end{gathered}
$$

where $\sigma_{i j}^{k}$ is a stress state in associated with $\dot{\varepsilon}_{i j}^{k}$ at yield stress $\sigma_{y} ; \quad \overline{\dot{\varepsilon}}$ is the effective strain rate $\overline{\dot{\varepsilon}}=\sqrt{\frac{2}{3} \dot{\varepsilon}_{i j} \dot{\varepsilon}_{i j}}$. The upper bound multiplier is calculated when the least multiplier is satisified by $\lambda_{U B}^{S D} \geq \lambda_{s}$

\subsection{Ratchet theorem}

The ratchet limit is the load limit that lies in between where accumulated plastic strain does not increase over a cycle and where accumulated plastic strain causes incremental failure. The ratchet limit can be 
obtained numerically by adopting a two-step procedure within the LMM framework. Firstly, the residual stress $\rho_{i j}^{r}$ and corresponding plastic strain range are calculated by incremental minimization of the energy function $I\left(\dot{\varepsilon}_{i j}^{k}, \lambda\right)$ for a predefined cyclic load:

$$
I\left(\dot{\varepsilon}_{i j}^{k}, \lambda\right)=\int_{V} \int_{0}^{\Delta t}\left(\sigma_{i j}^{k}-\sigma_{i j}\right) \dot{\varepsilon}_{i j}^{k} d t d V
$$

where $\sigma_{i j}^{k}$ denotes yield stress corresponding to the kinematically admissible strain rate $\dot{\varepsilon}_{i j}^{k}$.

Secondly, the ratchet limit is computed by performing a global minimization of the shakedown theorem with respect to an extra constant load $\hat{\sigma}_{i j}^{F}$ where the varying residual stress $\rho_{i j}^{r}(x, t)$ at a steady cycle enhances the cyclic elastic solution. Hence the cyclic elastic solution for ratchet limit analysis can be defined by:

$$
\hat{\sigma}_{i j}=\lambda \hat{\sigma}_{i j}^{F}+\hat{\sigma}_{i j}^{\Delta}(x, t)+\rho_{i j}^{r}(x, t)
$$

where $\hat{\sigma}_{i j}^{\Delta}(x, t)$ is an elastic solution with constant residual stress $\bar{\rho}_{i j}^{r}$.

Direct Steady Cycle Analysis (DSCA) in the LMM framework calculates the accumulated residual stress history. DSCA repeats cycles from $m=1$ to $m=M$. The each cycle $m$ has sub-cycles that represent the load instances from $k=1$ to $k=K$. The constant residual stress $\bar{\rho}_{i j}^{r}$ and varying residual stress $\Delta \rho_{i j}^{r}$ corresponding to the elastic solution can be calculated as equations (7) and (8):

$$
\begin{gathered}
\bar{\rho}_{i j}^{r}=\sum_{m=1}^{M} \sum_{k=1}^{K} \Delta \rho_{i j}^{r}\left(x, t_{k}\right)_{m} \\
\rho_{i j}^{r}\left(x, t_{k}\right)=\bar{\rho}_{i j}^{r}(x)+\sum_{l=1}^{k} \Delta \rho_{i j}^{r}\left(x, t_{l}\right)_{M}
\end{gathered}
$$

The converged plastic strain developed at a time $t_{k}$ can be expressed as: 


$$
\Delta \varepsilon_{i j}^{p}\left(x, t_{k}\right)=\frac{1}{2 \bar{\mu}_{n}\left(x, t_{k}\right)}\left[\hat{\sigma}_{i j}^{\Delta^{\prime}}\left(x, t_{k}\right)+\rho_{i j}^{r^{\prime}}\left(x, t_{k}\right)\right]
$$

where $\bar{\mu}$ is the iterative shear modulus calculated by the LMM and (') indicates deviatoric stress and strain.

Adopting the von-Mises yield criterion for an elastic perfectly plastic material, the upper bound multiplier $\lambda_{U B}^{R C}$ for the ratchet limit can be defined by:

$$
\lambda_{U B}^{R C}=\frac{\int_{V} \sum_{k=1}^{K} \sigma_{y} \bar{\varepsilon}\left(\Delta \varepsilon_{i j}^{k}\right) d V-\int_{V} \sum_{k=1}^{K}\left[\hat{\sigma}_{i j}^{\Delta}\left(t_{k}\right)+\rho_{i j}^{r}\left(t_{k}\right)\right] \Delta \varepsilon_{i j}^{k} d V}{\int_{V} \hat{\sigma}_{i j}^{F}\left(\sum_{k=1}^{K} \Delta \varepsilon_{i j}^{k}\right) d V}
$$

where $\bar{\varepsilon}$ is the effective strain $\bar{\varepsilon}\left(\Delta \varepsilon_{i j}^{k}\right)=\sqrt{\frac{2}{3} \Delta \varepsilon_{i j}^{k} \Delta \varepsilon_{i j}^{k}}$. Based on this iterative procedure, the LMM calculates the least upper bound limit for the ratchet limit.

In the case of the lower bound multiplier $\lambda_{L B}^{R C}$ for the ratchet limit, the constant residual stress is taken into account simultaneously with the varying residual stress field at every iterative process. Thus, the lower bound multiplier can be defined by modifying Eq.(1) with Eq.(6):

$$
f\left(\lambda_{L B}^{R C} \hat{\sigma}_{i j}^{F}+\hat{\sigma}_{i j}^{\Delta}+\rho_{i j}^{r}\right) \leq 0
$$




\section{Problem descriptions}

\subsection{The pipe bend model}

Two pipe system configurations are investigated, one with two directly connected pipe bends and one in which the bends are connected by a horizontal straight pipe section. Both pipe arrangement is shown in Figure 1. One without the horizontal pipe is the main geometry for this analysis, whereas the other one is used only for parametric studies. The pipe dimensions conform to U.S standard pipe size 10inch NPS Schedule 40. The mean pipe diameter is $D_{m}$, the straight end runs are length $L$ and the bend connecting run length is $L_{m}$. It is considered that the pipe bend system can be defined as two ratios: $r / t$ and $R / r$, where $r$ is the mean radius of the pipe; $t$ is the wall thickness of the pipe; $R$ is the bend radius. Dimensions of the configuration are summarized in Table 1. The pipe bend behaviour is generally described in terms of these ratios and the pipe bend parameter or pipe factor $h$ :

$$
h=\frac{R t}{r^{2}}=\frac{R / r}{r / t}
$$

Table 1. Pipe bend dimensions and the two straight pipes (mm).

\begin{tabular}{cccccc}
\hline $\mathbf{D}_{\mathbf{m}}$ & $\mathbf{R}$ & $\mathbf{t}$ & $\mathbf{L}=\mathbf{5} \mathbf{D}_{\mathbf{m}}$ & $\mathbf{r} / \mathbf{t}$ & $\mathbf{R} / \mathbf{r}$ \\
\hline $\mathbf{2 6 3 . 7 8}$ & 381 & 9.27 & 1318.9 & 14.23 & 2.89 \\
\hline
\end{tabular}

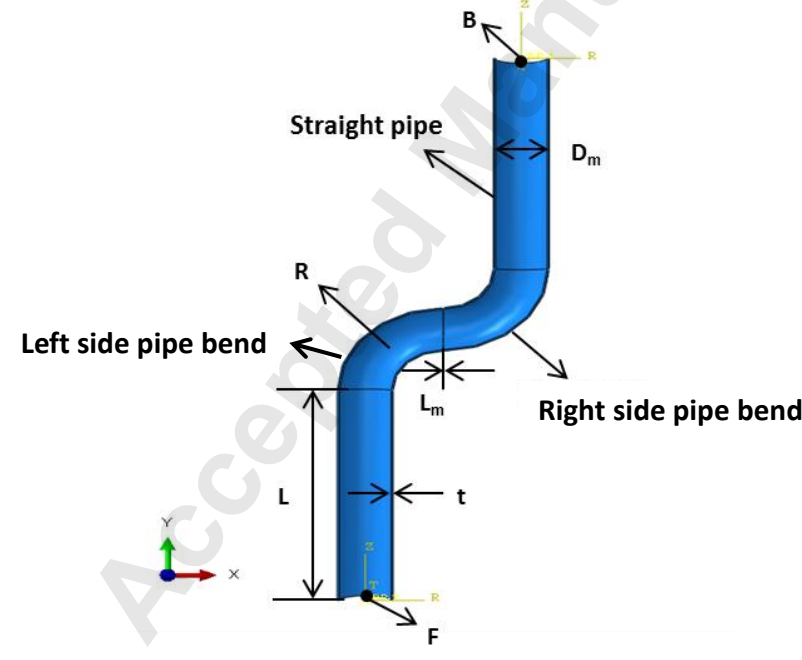

(a)

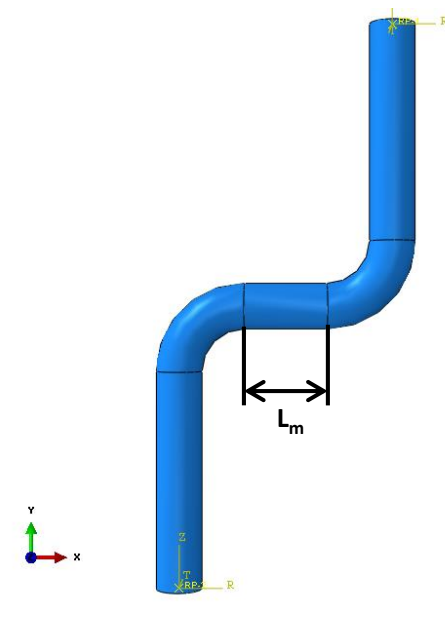

(b)

Figure 1. The geometry of the pipe configuration with the horizontal straight pipe sections: (a) $L_{m}=0.0 \mathrm{~mm}$ and (b) $L_{m}=500.0 \mathrm{~mm}$. 
Complete 3D finite element models of the configurations in Abaqus using 3D solid C3D20R quadratic elements, as shown in Figure 2. Following a mesh refinement study, the configuration of the main pipe system has meshed with 13,800 elements. Three elements are defined through the wall thickness. Each pipe bend has 25 elements along its length and 50 around its circumference. The vertical straight runs $L$ has meshed with fifty elements with the mesh refined towards the intersection with the pipe bend.

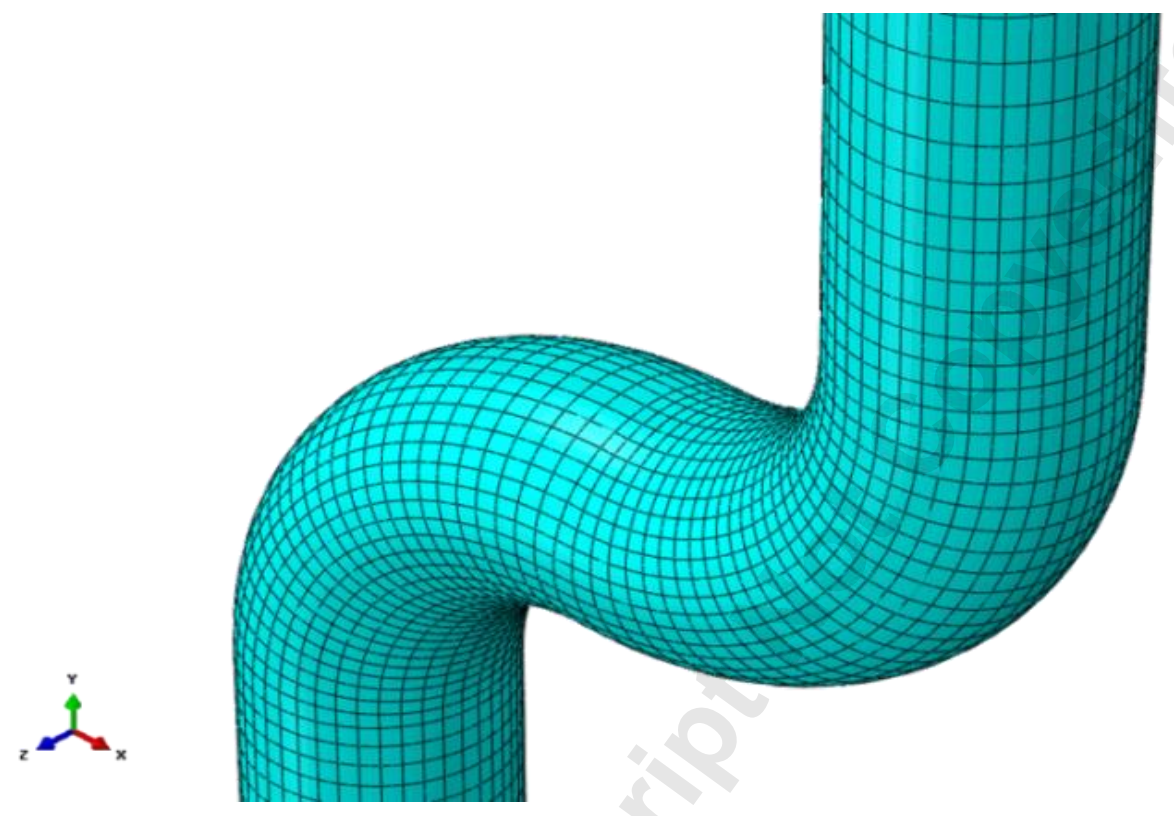

Figure 2. The meshed model with 3D solid elements.

\subsection{Material properties and boundary conditions}

The material investigated is type 304 stainless steel, previously considered in [18]. Young's modulus is 193.74 GPa and Poisson's ratio is 0.2642 . Temperature-dependent yield stresses up to $550^{\circ} \mathrm{C}$ are listed in Table 2 and the material model is elastic perfectly plastic.

Table 2. Temperature dependent yield stress

\begin{tabular}{llllllll}
\hline Temperature $\left[{ }^{\circ} \mathrm{C}\right]$ & 20 & 100 & 200 & 300 & 400 & 500 & 550 \\
\hline$\sigma_{\mathrm{y}}[\mathrm{MPa}]$ & 271.93 & 253 & 229 & 207 & 188 & 172 & 156 \\
\hline
\end{tabular}

As shown in Figure 1, a reference node is created on both the bottom and top of the pipe system: F for the bottom and $B$ for the top of the pipe system. The kinematic coupling is constructed between each reference node and whole surfaces of the pipe system in the same $x-z$ plane and it allows the expansion/contraction in the radial direction. 
Figure 3 illustrates a loading pattern of the cyclic bending moment and the thermal gradient over the pipe system configuration. The cyclic thermal load is implemented by applying the temperature difference between the external and internal surfaces of the pipe system as shown in Figure 3 (b). For the cyclic thermal loading, the most severe thermal loading condition during "start-up" is applied as a through wall thermal gradient with the temperature $550^{\circ} \mathrm{C}$ at the inside surface and $20^{\circ} \mathrm{C}$ at the outside surface, so that. The material is assumed to have a thermal conductivity of $43 \mathrm{Wm}^{-1} \mathrm{~K}^{-1}$ and the thermal expansion coefficient of $1.7 \times 10^{-5}{ }^{\circ} C^{-1}$. By applying an equation to constrain the top surface of the right side vertical pipe as a plane condition, the thermal expansion effect of a long pipe is achieved.

To implement the cyclic out-of-plane bending, a clockwise moment about the $\mathrm{x}$-axis is applied on node B. An analytic equation to calculate the limit moment $M_{L}$ is used for the normalisation of the computed moment value as given by Eq. (13):

$$
M_{L}=\sigma_{y} D_{m}^{2} t
$$

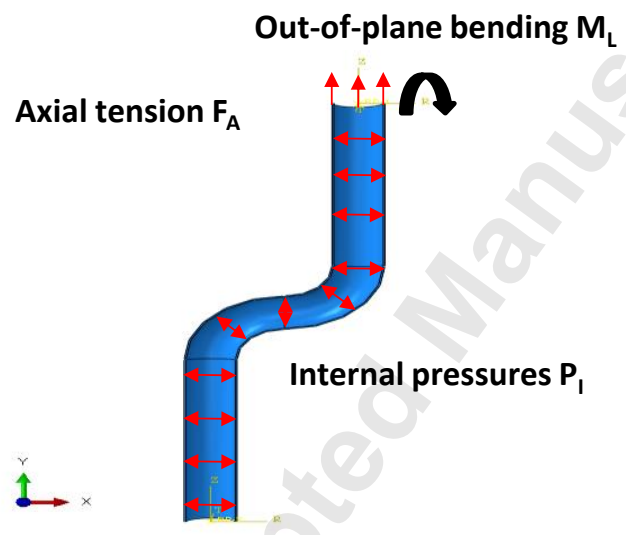

(a)

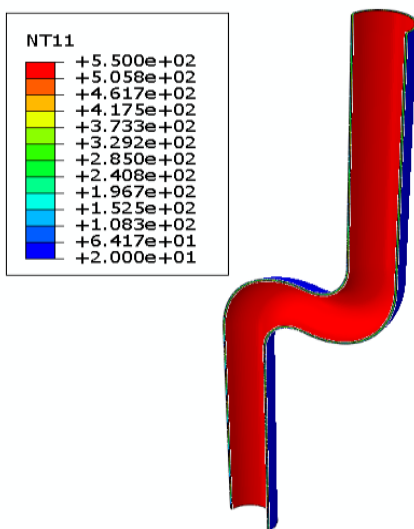

(b)

Figure 3. (a) configuration of the bending and internal pressures and (b) thermal gradient through a wall thickness.

The internal surfaces of pipe configuration have constant pressures. It is assumed that the pipe bends are in a closed-end condition, which generates the axial tension on the top side of the pipe system proportionally to the internal pressure. Analytic equations are employed to normalise the internal pressure and axial tension, as given equations (14) and (15): 


$$
P_{L}=\frac{2}{\sqrt{3}}\left(2 \sigma_{y} t / D_{m}\right)
$$

$$
F_{A}=P_{L} D_{m} / 4 t
$$

where $P_{L}$ is the limit pressure $; F_{A}$ is the axial tension.

Loading paths between the cyclic out-of-plane bending and constant pressure (Loading Type A), cyclic out-of-plane bending and cyclic thermal load (Loading Type B), and cyclic thermal load and constant pressure (Loading Type C) conform to the classic Bree problem. A cuboid loading domain for the three load combinations is considered to present a shakedown limit domain of the pipe bends in a threedimensional loading space. The loading paths and the loading domain are illustrated in Figure 4.

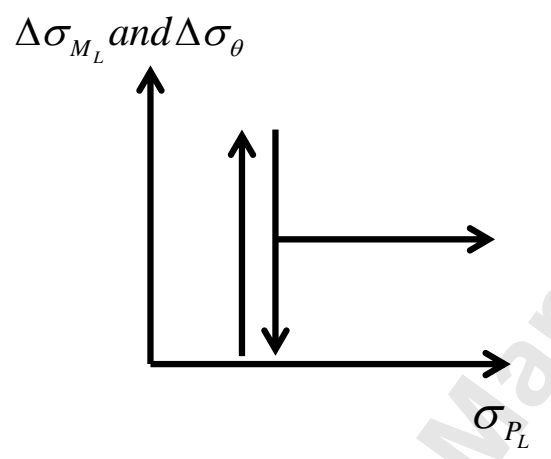

(a)

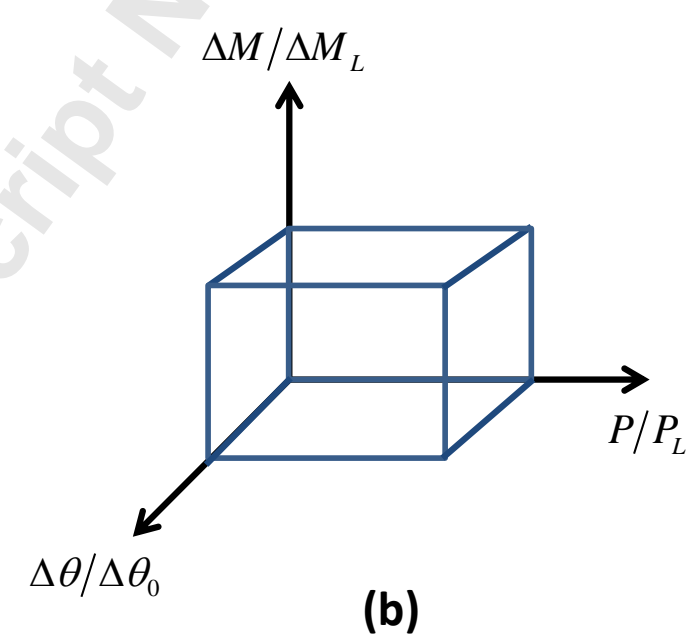

(b)

Figure 4. (a) loading paths for the three loading type A, B and C and (b) a loading domain for the three load combinations. 


\section{Cyclic thermo-mechanical loading and constant internal pressure}

Figure 5 shows three linear elastic solutions of the pipe system under the three individual loads: thermal loading, out-of-plane bending, and internal pressure. The thermal load produces the maximum tensile stress at the outside of the pipe structure but the compressive stress at the inside due to the nonisothermal effects. The thermal expansion coefficient of the material is a critical factor that leads to these thermal stresses. The bending moment causes the clockwise overturning moment to the pipe bend so that the flank of the left side pipe bend has the maximum equivalent stress. The internal pressures cause the anticlockwise moment to the pipe bend so that the intrados of the left side pipe bend has the maximum equivalent stress. Among the three different loads, the maximum equivalent stress value is in order of out-of-plane bending, thermal load, and constant pressure.
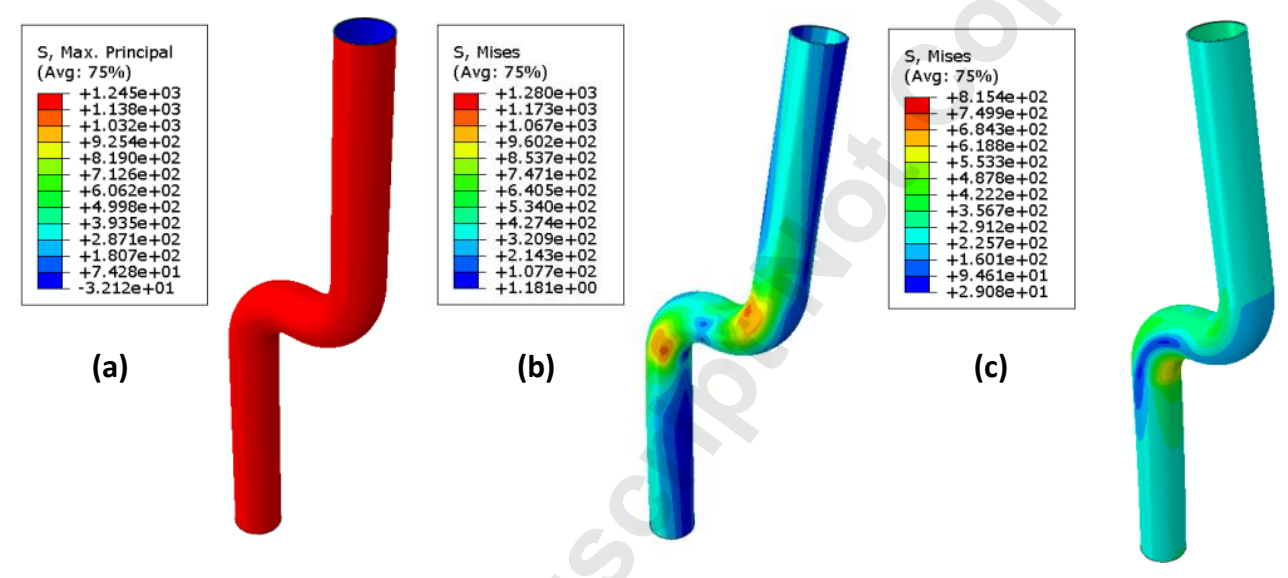

Figure 5. Linear elastic solutions; (a) maximum principal stress $[\mathrm{MPa}]$ under thermal load, (b) equivalent stress $[\mathrm{MPa}]$ under out-of-plane bending moment and (c) equivalent stress $[M P a]$ under internal pressures. 


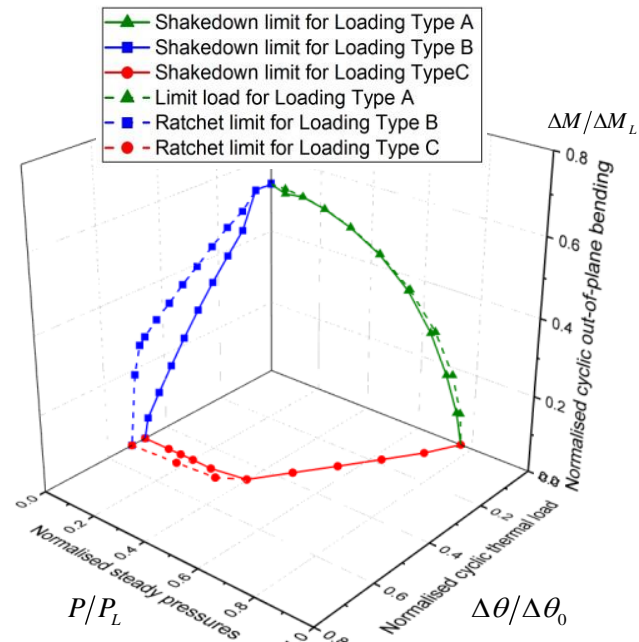

(a)

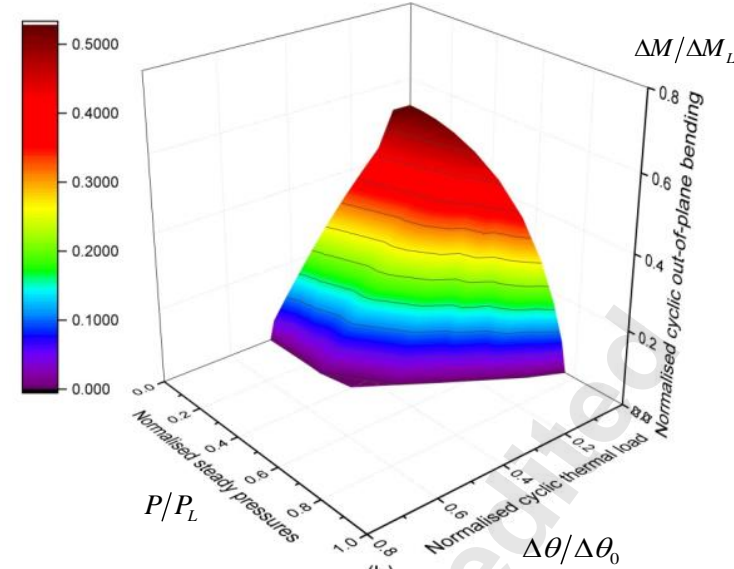

(b)

Figure 6. (a) Shakedown and ratchet limit boundaries of the pipe system subjected to cyclic thermal load, cyclic out-of-plane bending and constant internal pressure and (b) shakedown domain in the three-dimensional loading space.

The cyclic plastic analysis is performed by the LMM for the pipe system subjected to the three load cases defined as Loading Type A, Loading Type B and Loading Type C in Section 3.2. The shakedown and ratchet limit boundaries under the three load types are presented in Figure 6(a). Figure 6(b) illustrates a shakedown limit domain of the pipe structure in a three-dimensional loading space shown in Figure 4(b).

\section{(1) Case 1: Loading Type A}

The limit pressure and limit moment of the pipe configuration under Loading Type A reduces to 76\% and 53\% respectively against the reference pressure and bending moment. We can see that the out-ofplane bending makes more critical impacts on the load bearing capacity of the pipe system than the constant pressures.

The normalised shakedown limit without any pressure applied is called the reverse plasticity limit. For cyclic loading beyond this limit, a certain range of plastic deformation develops as a closed loop until it reaches the ratchet limit. The normalised limit load, shakedown and ratchet limits without any bending moment is known as the limit pressure. For cyclic loading exceeding this limit, the structural failure occurs immediately. One interesting point associated with the shakedown limit boundary under cyclic out-of-plane bending is that the reverse plasticity limit is almost the same as the normalised limit moment. Therefore, the shakedown limit boundary for $P / P_{L}<0.4$ is almost indistinguishable from the ratchet limit boundary. There are some margins appeared for $P / P_{L}>0.4$ but hard to define the ratchet limit boundary. Upon the case, we need to consider the shakedown limit boundary is the same as the 
ratchet limit boundary as a conservative manner. It is noteworthy that the previous study [18] shows that the pipe system under cyclic in-plane bending has a completely different shape of the shakedown limit boundary from the one under cyclic out-of-plane bending. The cyclic in-plane bending produced the boundary which is very similar to Bree-like diagram with large margins between the limit load and the shakedown boundaries. Therefore, the effects of the bending direction on the cyclic plasticity of the concerned pipe system configuration needs to be considered when designing the allowable load level.

\section{(2) Case 2: Loading Type B}

When it comes to the ratchet limit boundary, the pipe bend structure can withstand the loading at 53\% under cyclic out-of-plane bending and 54\% under cyclic thermal load, compared to their reference bending moment and temperature respectively. Regarding the reverse plasticity limit, the normalised value by the cyclic thermal load is almost the same as by the cyclic out-of-plane bending. Hence the effects of cyclic thermal load on the pipeline integrity require serious considerations.

Different from the shape of the shakedown limit boundary under Loading Type A, Loading Type B develops a shakedown limit boundary of a triangular shape which merges to the reverse plasticity limit of cyclic out-of-plane bending for $\Delta M / \Delta M_{L}>0.5$. Hence, the ratchet limit under Loading Type $\mathrm{B}$ should be considered as the shakedown limit boundary where $\Delta M / \Delta M_{L}>0.5$. However, the margin between the ratchet limit boundary and the shakedown limit boundary becomes larger as the cyclic thermal load increases up to the reverse plasticity limit of cyclic thermal load, $\Delta \theta / \Delta \theta_{0}=0.54$. It is noteworthy that the thermal ratcheting does not occur in the Bree problem under the pure cyclic thermal load, but it does in the double pipe bend structure where $\Delta \theta / \Delta \theta_{0}>0.54$. Therefore, the allowable load level should be selected from below the shakedown limit boundary.

\section{(3) Case 3: Loading Type C}

Shakedown limit boundary under Loading Type $\mathrm{C}$ shows very similar shape to the exemplary Bree diagram. Where $P / P_{L}<0.3$, the shakedown limit boundary maintains the constant reverse plasticity limit, and afterward slightly decreases until $P / P_{L}=0.4$. The margin that shows the reverse plasticity response is small due to the thermal ratchet limit. Therefore, the proper load level should be selected under the shakedown limit boundary. 


\section{Further Numerical Studies and Discussions}

Figure 7 presents the changes in the bend characteristics $(R / r$ and $r / t)$ and the horizontal pipe run $\left(L_{m}\right)$ of the pipe bend system. In this numerical study, the effects of the varying geometry on the cyclic plasticity will be investigated under cyclic thermal load and cyclic out-of-plane bending respectively, with constant pressure. The same equations from Eq.(13) to Eq.(15) are employed for the normalisation process and the computed reference loads are summarised in Table 3.

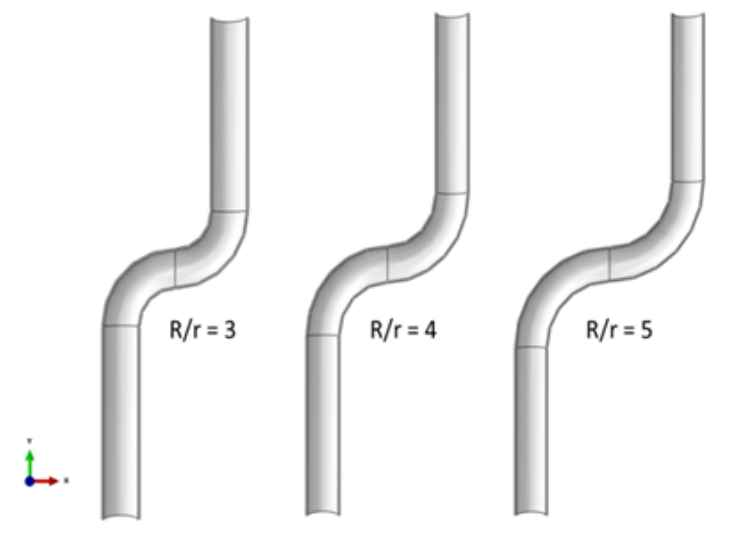

(a)

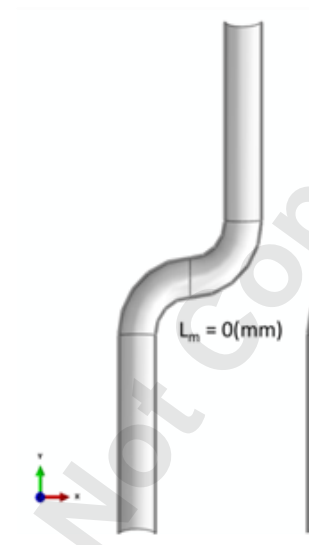

(b)

Figure 7. (a) $\mathrm{R} / \mathrm{r}$ ratio $3,4,5$ and (b) horizontal pipe length $L_{m}=0 \mathrm{~mm}, 250 \mathrm{~mm}, 500 \mathrm{~mm}$.

Table 3. Reference loads computed for each $\mathbf{r} / \mathrm{t}$ ratio.

\begin{tabular}{cccc}
\hline$r / t$ & $F_{A}[\mathrm{MPa}]$ & $P_{L}[\mathrm{MPa}]$ & $M_{L}[\mathrm{Nmm}]$ \\
\hline 5 & 157 & 62.80 & $4.9 \mathrm{E}+08$ \\
10 & 157 & 31.40 & $2.5 \mathrm{E}+08$ \\
20 & 157 & 15.70 & $1.2 \mathrm{E}+08$ \\
\hline
\end{tabular}

\subsection{Cyclic thermal load and constant internal pressures}

In this section, the effects of the geometry changes on the cyclic plasticity of the pipe bend under cyclic thermal load and constant internal pressure are investigated. Figure 8 shows a comparison of the shakedown and ratchet limit boundaries for changing $R / r$ ratio against a fixed $r / t=5$. Internal pressures are normalised by pressures in Table 3 and a reference temperature $\Delta \theta_{0}=550^{\circ} \mathrm{C}$ is employed to normalise the cyclic temperature load. 
The constructed shakedown limit boundaries have a very similar shape to the typical Bree diagram. The results provide interesting observations that the calculated reverse plasticity limit is the same regardless of changes of $R / r$ ratio. The variations of $R / r$ ratios (3, 4 and 5) have minor effects on the thermal stress magnitude of the pipe structure. It demonstrates that the reverse plasticity limit reported in Figure 6 (a) is also the same as in Figure 8. Also, Chen et al. presented the effect of cyclic thermal load on a single elbow bend with the varying $R / r$ ratio, it confirms that reverse plasticity limits are very close to each other [16].

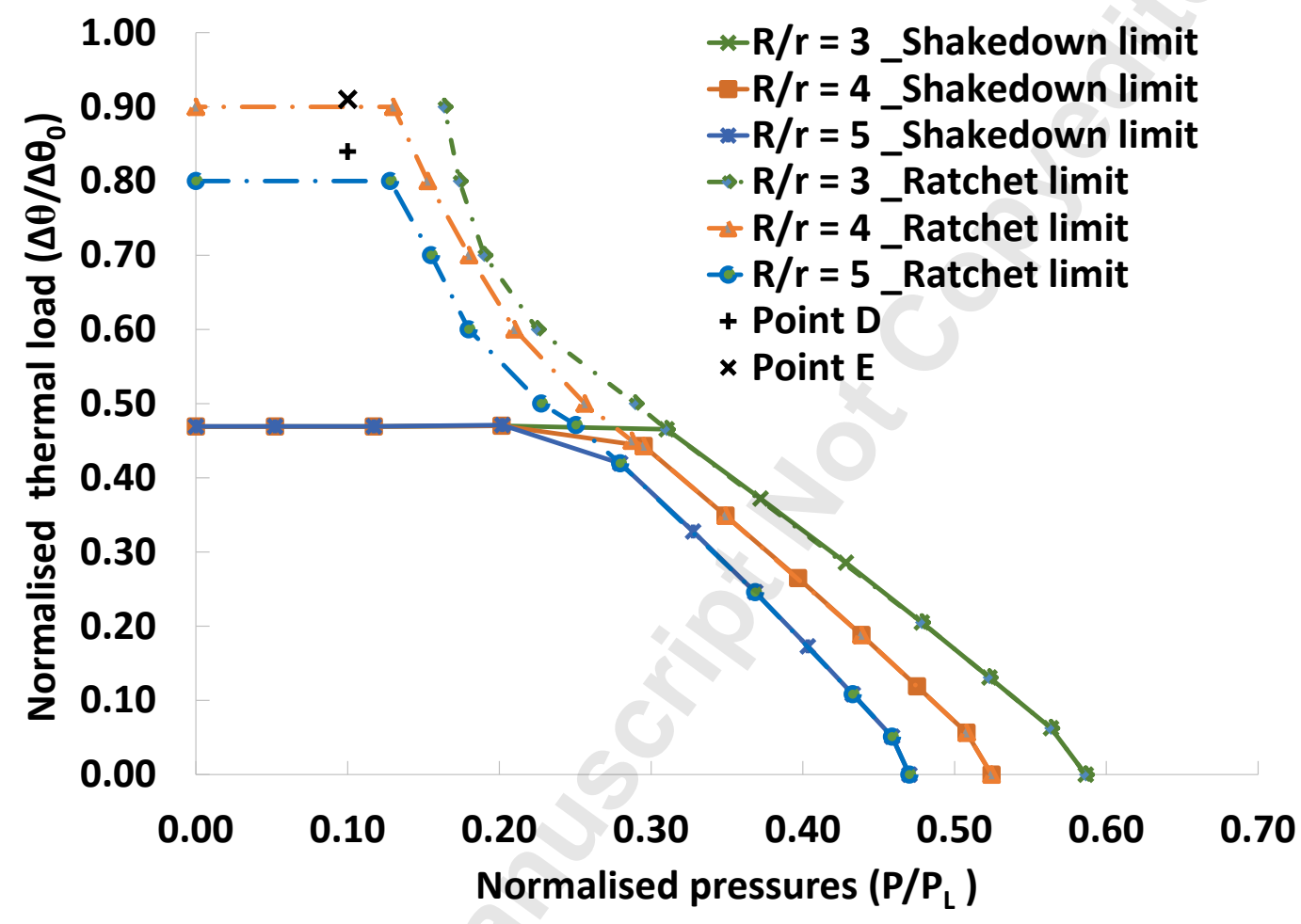

Figure 8. Structural response interaction boundaries of the pipe system $(r / t=5)$ subjected to cyclic thermal load and constant internal pressure against variations of $R / r$ ratio.

Ratchet limit boundaries of $R / r$ ratio of 4 and 5 have the thermal ratchet limit, thus they have a similar form with a shakedown limit boundary of the Bree diagram. However, no thermal ratchet limit is observed for $R / r=3$ below the normalised thermal load of 1.0. In Figure 8, two cyclic loading points $\mathrm{D}\left(\Delta \theta / \Delta \theta_{0}=0.85 \& P / P_{L}=0.1\right)$ and $\mathrm{E}\left(\Delta \theta / \Delta \theta_{0}=0.92 \& P / P_{L}=0.1\right)$ are created to validate the ratchet limit boundary of $R / r$ ratio of 4 and 5. The full incremental cyclic analysis is performed to evaluate the plastic strain increment over a number of load instances. As results of the validation, Figure 9 shows the clear ratcheting response which appears in the $R / r$ ratio of 4 and 5 , whereas $R / r$ ratio 3 exhibits no ratcheting response but alternating plasticity. From the results, we can see that the higher temperature field affects pipe bends and the reverse plasticity zone becomes smaller as the $R / r$ 
ratio increases. The cyclic thermal load affects ratchet limit boundary but merely shakedown limit boundary for variations of $R / r$ ratio.

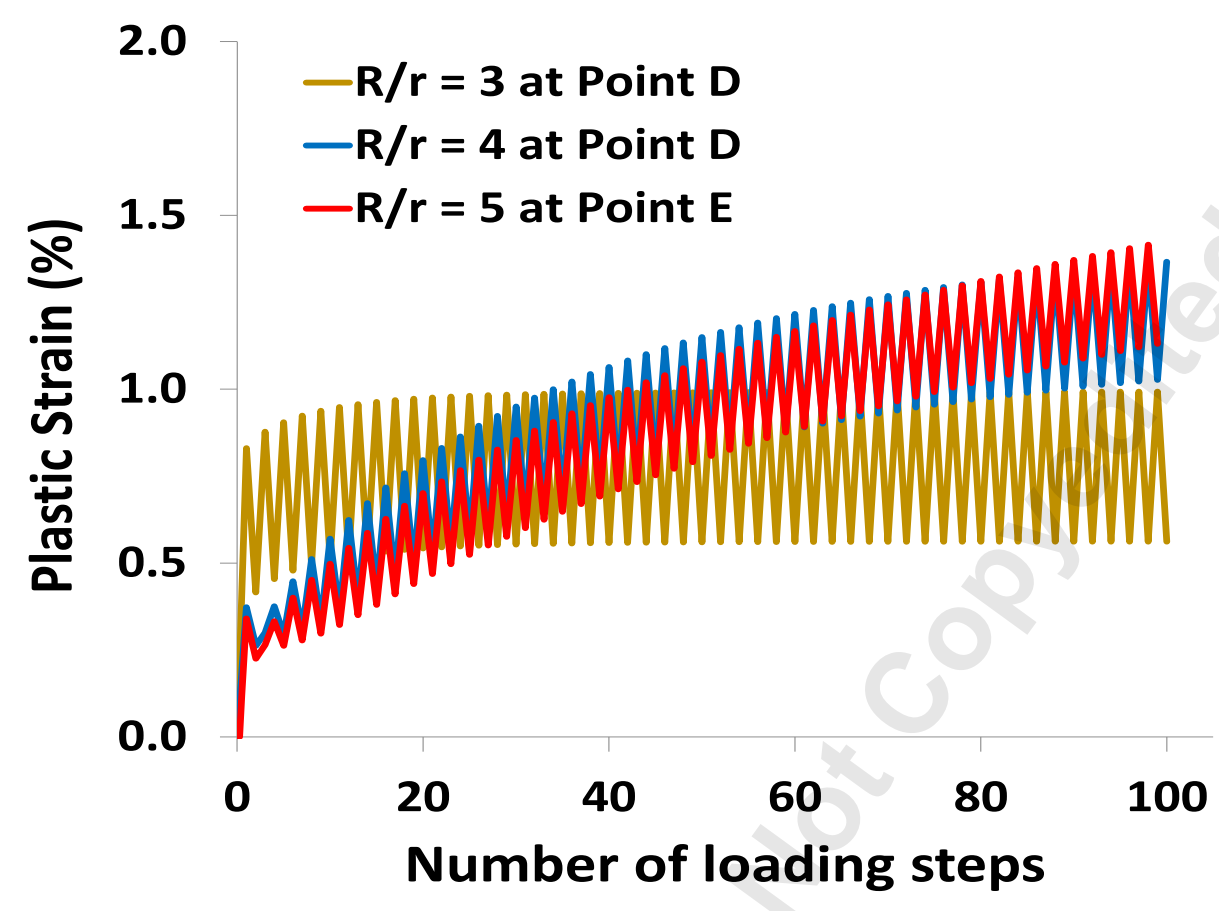

Figure 9. Plastic strain history (PEMAG) of $R / r$ ratio 3 and 4 at cyclic loading point $D$ and of $R / r$ ratio 5 at cyclic loading point $E$.

Further study is performed for investigating shakedown limit boundaries of the same pipe structure subjected to the cyclic thermal load, constant internal pressure, and constant out-of-plane bending. The same reference pressure and temperature are adopted for the normalisation. Figure 10 depicts the resulting shakedown limit boundaries with variations of $R / r$ ratio $(3,4$, and 5) against a fixed $r / t=5$. Although the constant out-of-plane bending moment is applied together with the pressure, the shape of shakedown limit boundaries is similar to the Bree diagram. The reverse plasticity limits do not change for $P / P_{L} \& M / M_{L}<0.2$, regardless of the variation of $R / r$ ratio, but the combined constant pressure and bending moment are reduced to $11 \%, 7 \%$, and $5 \%$ respectively as $R / r$ ratio increases 3,4 , and 5 . Therefore, it is deduced that the geometry changes under cyclic thermal load and constant pressure (or combined with the bending moment) have minor effects on the shakedown limit boundaries but considerable impacts on thermal ratchet limit. 


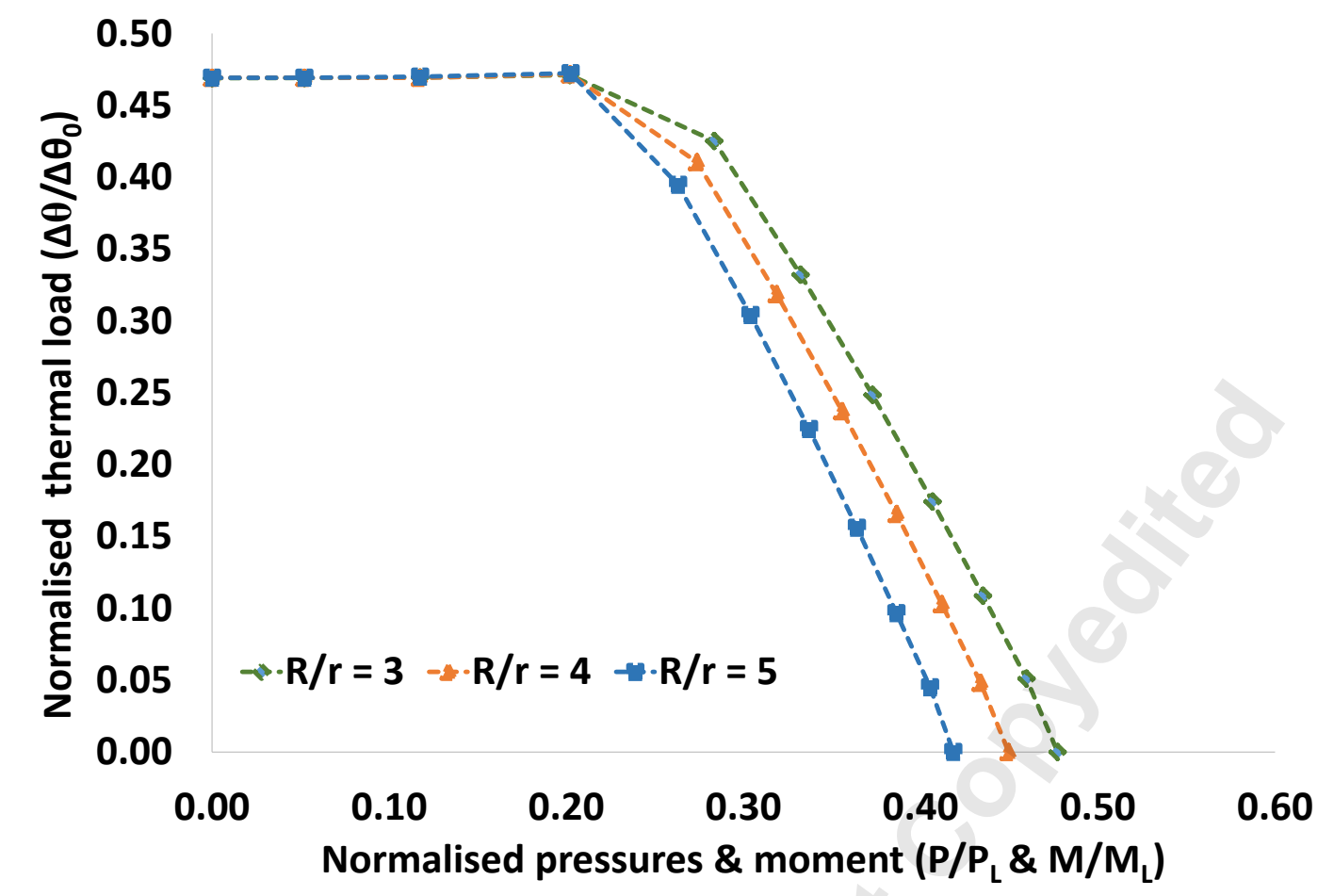

Figure 10. Structural response interaction boundaries of the pipe system under the constant out-of-plane bending, constant internal pressure, and cyclic thermal load against variations of $R / r$ ratio.

\subsection{Cyclic out-of-plane bending and constant internal pressures}

\subsubsection{Geometry effects of the pipe bend characteristics}

In this section, the effects of changing $R / r$ ratios $(3,4$, and 5) on the cyclic plasticity of the pipe bend ( $r / t=5,10$, and 20) under cyclic out-of-plane bending and constant internal pressure are investigated. Figure 11 shows structural response interaction boundaries under the geometry changes, where LM curve is the limit load boundary and SD \& RC curves are the shakedown limit and the ratchet boundary respectively. Table 1 shows the other geometries which are the vertical straight pipe $L$ and the mean diameter of $D_{m}$.

From the results, the normalised limit moment and the reverse plasticity limit at zero pressures are very close to each other. It means that the changes in geometry seldom affect the reverse plasticity limit under cyclic out-of-plane bending. Besides, as $r / t$ ratio decreases, the reverse plasticity limit is likely to enhance but the limit pressure reduces. Thus, the pipe system with larger $R / r$ ratio has higher endurance against the cyclic out-of-plane bending, but lower endurance against the internal pressure. 

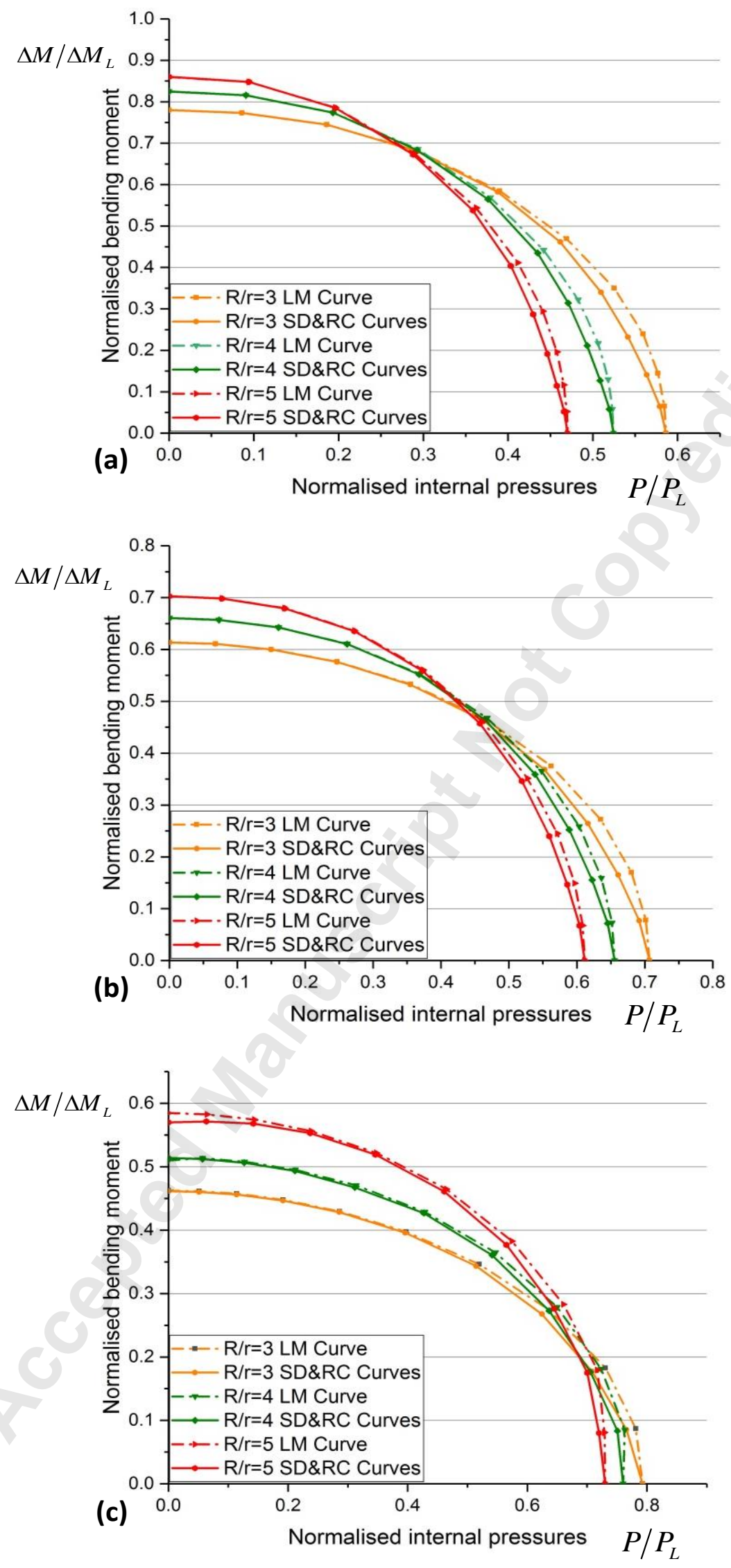

Figure 11. Structural response interaction boundaries of the pipe system under the effects of $\mathrm{R} / \mathrm{r}$ ratio: a) $r / t=5, \mathrm{~b}) r / t=10$, and c) $r / t=20$. 
In the case of $r / t=5$ (thick-walled), shakedown limit boundaries for $P / P_{L}<0.3$ are equal to corresponding limit load boundaries. The margins between the limit load and shakedown limit boundaries begin to form where $P / P_{L}>0.3$ but they are small. Although the margins slightly increase by increasing of $R / r$ ratio, the ratchet limit boundary is too small to be constructed. Hence it is recommended that the shakedown limit boundary should be dealt with the ratchet limit boundary. The thick-walled pipe has lower endurance capacity against the constant pressures than the cyclic out-ofplane bending. With increasing of $R / r$ ratio, the limit moment and reverse plasticity limit increase for $P / P_{L}<0.3$, but decrease for $P / P_{L}>0.3$. Compared to the previous study [18], cyclic out-of-plane bending generates a larger elastic shakedown limit boundary but smaller reverse plasticity zone. Therefore, the thick-walled application is an appropriate design for a piping network operated under a high level of cyclic out-of-plane bending.

In the case of $r / t=10$ and $r / t=20$ (thin-walled), the shakedown limit boundaries are also very adjacent to limit load boundaries. They have very small margins for each $R / r$ ratio so that the shakedown limit boundary can replace to ratchet limit boundary. With an increase of $r / t$ ratio, the limit pressure decrease but the reverse plasticity limit increases. With an increase of $R / r$ ratio, the pipe system with $r / t=10$ has higher resistance to the bending for $P / P_{L}<0.45$ but reduces for $P / P_{L}>0.45$. The pipe system with $r / t=20$ shows the higher bending resistance for $P / P_{L}<0.68$, whereas lower bending resistance for $P / P_{L}>0.68$. Compared to the previous study, reverse plasticity limits for $r / t=20$ are higher under cyclic out-of-plane bending than cyclic in-plane bending. Therefore, we can expect that the pipe bends have higher endurance capacity against cyclic bending moments in the out-of-plane direction than the in-plane direction.

The previous study [18] derived the relationships between reverse plasticity limit $R P_{\lim }^{\text {in-plane }}$ and the bend characteristic $h$ and between limit pressures $L P_{\text {lim }}^{\text {in-plane }}$ and the bend characteristic $h$ as below two equations (16) and (17).

$$
\begin{aligned}
& R P_{\lim }^{\text {in-plane }}=-0.784 h^{2}+1.6242 h+0.0492 \\
& L P_{\lim }^{\text {in-plane }}=0.2247 h^{2}-0.6233 h+0.8751
\end{aligned}
$$

From the numerical results in Figure 11, we develop another relationships between the bend characteristic $h$ and reverse plasticity limit $R P_{\text {lim }}^{\text {out-of-plane }}$ and between the bend characteristic $h$ and a 
ratio $\left(R T=R P_{\lim }^{\text {out }- \text { f - plane }} / R P_{\lim }^{\text {in-plane }}\right)$ and by adopting the Quadratic Regression method as given Eq. (18) and Eq.(19).

$$
R P_{\lim }^{\text {out-of-plane }}=-0.5032 h^{2}+1.0227 h+0.3367
$$

$$
R T=1.4312 h^{2}-2.3624 h+1.9154
$$

Trends for the newly derived equations are illustrated in Figure 12 and R-squared value of the all equations from Eq.(16) to Eq.(19) are higher than 0.98.

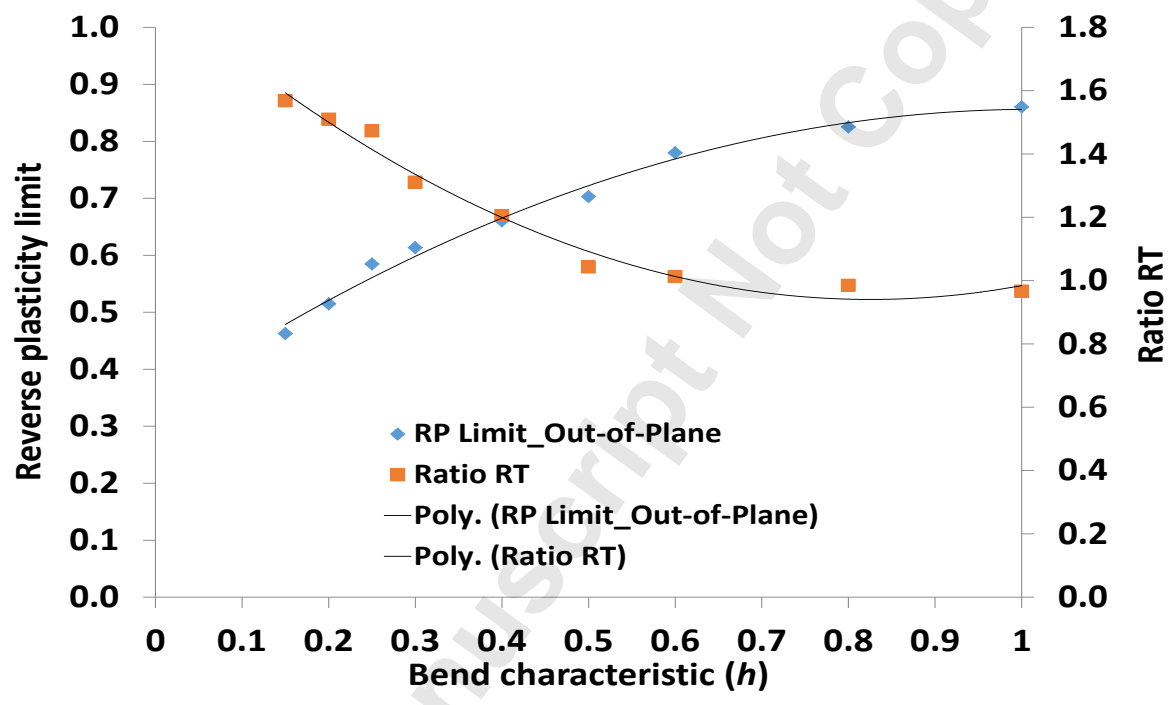

Figure 12. Derived relationships from equations (18) and (19).

The developed semi-empirical equations can aid a piping system designer to estimate the reverse plasticity limit and limit pressures of the pipe system against varying geometry effects under both inplane and out-of-plane bending moments, without performing the FE analysis.

\subsubsection{Geometry effects of the horizontal straight pipe}

In this section, the effects of changing length of the horizontal straight pipe $(0,250,500 \mathrm{~mm})$ on the cyclic plasticity of the pipe system $(r / t=5,10$, and $20 \& R / r=2.89)$ under cyclic out-of-plane bending and constant internal pressure are investigated. Figure 13 presents structural response interaction boundaries under the horizontal length changes. Table 1 shows the other geometries which are the vertical straight pipe $L$ and the mean diameter of $D_{m}$. 

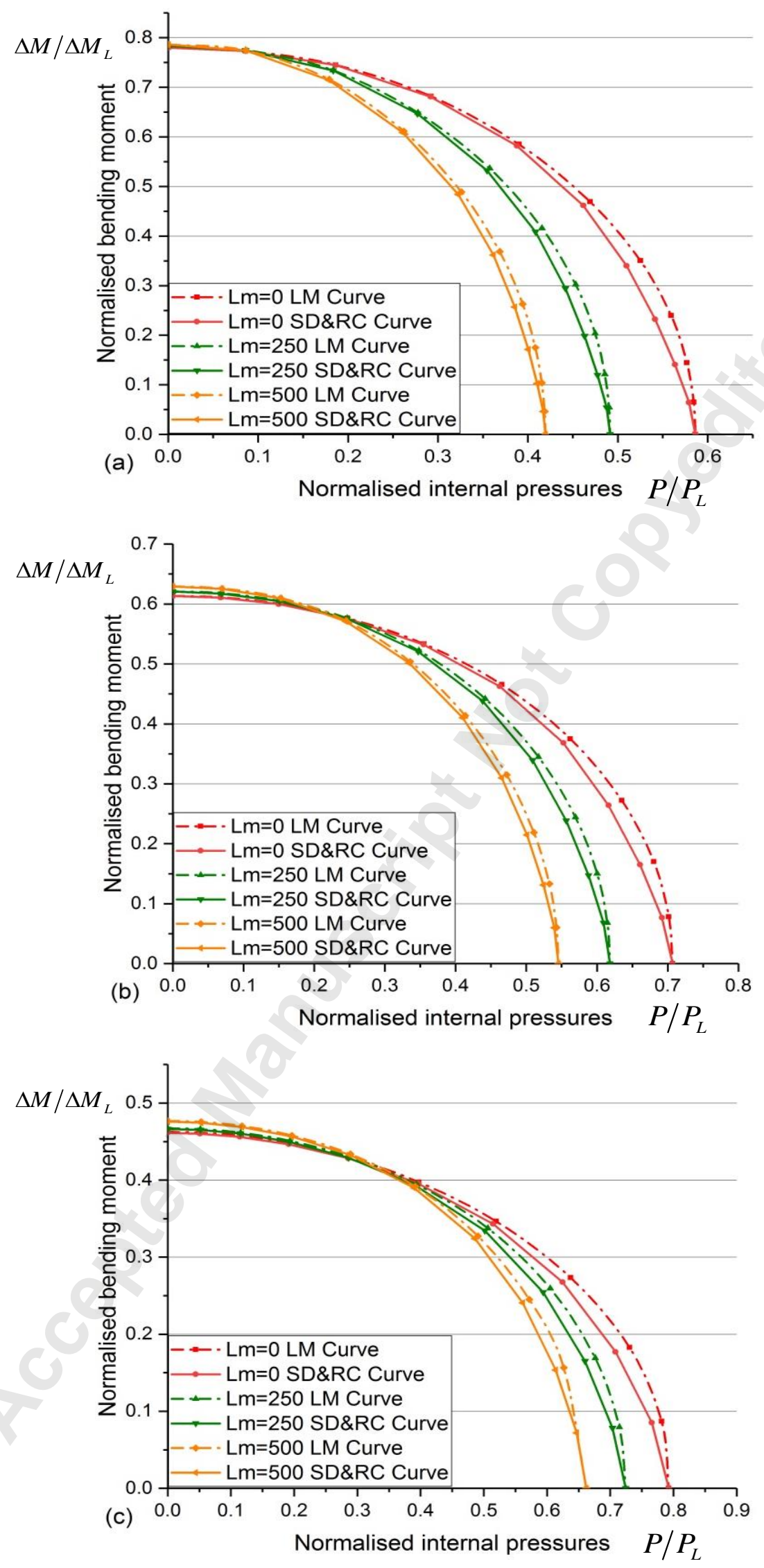

Figure 13. Structural response interaction boundaries of the pipe system under the effect of the horizontal pipe length $L_{m}$ : a) $r / t=5$, b) $r / t=10$, and c) $r / t=20$. 
From the results, we observe that limit pressures increase but reverse plasticity limit decreases as the length $L_{m}$ decrease. However, the variation of the reverse plasticity limit is very small. Under the cyclic out-of-plane bending, the reverse plasticity limits are very close to their corresponding limit moments at zero pressure, which means changes of the horizontal length have no effects on the size of the alternating plasticity zone which is referred to the margin. Owing to small margins between limit load and shakedown limit boundaries, the ratchet limit boundary should be replaced to the shakedown limit boundary. Contrary to the effects of the horizontal pipe length under cyclic in-plane bending [18], the horizontal pipe length under cyclic out-of-plane bending has minor effects on the reverse plasticity limit but significant impacts on the limit pressures.

In the case of $r / t=5$ (thick-walled), regardless of the length of $L_{m}$, we can see the reverse plasticity limit is identical to the normalised limit moment. However, limit pressures decrease with increasing of the length $L_{m}$. The margins between the limit load and the shakedown limit boundaries appear where $P / P_{y}>0.2$ but very minimal. In terms of the endurance, the pipe system with $r / t=5$ has larger normalised moment values than normalised pressure values despite the existence of horizontal pipe length. Thus, the thick-walled pipe with the horizontal pipe runs is a suitable application for a high level of cyclic out-of-plane bending expected during operations.

In the case of $r / t=10$ and $r / t=20$ (thin-walled), reverse plasticity limits and normalised limit moment values at zero pressures are nearly equal. The maximum change in the reverse plasticity limit between each horizontal length is 0.1 . The limit pressure decreases as the length $L_{m}$ increases. The margins appears at where $P / P_{y}>0.26$ and $P / P_{y}>0.39$, respectively, but still too narrow to construct the ratchet limit boundaries. Compared to the previous study, the pipe systems have a greater bending resistance of $15 \%$ and $20 \%$ respectively. It observed that changes in the horizontal straight pipe length make less impact on the reverse plasticity limit but effective on internal pressures. In particular, the pipe structure of $r / t=5$ with $L_{m}=500 \mathrm{~mm}$ has over $20 \%$ pressure reduction from the pipe structure without the horizontal pipe. Therefore, the horizontal pipe length should be designed as short as possible if thick walled pipe bends subjected to high internal pressure operation.

These studies show the effects of the horizontal pipe length on the integrity of the pipe structure, which makes significant impacts on the constant pressures but negligible impacts on the cyclic out-of-plane bending. Due to the small margins, plastic collapse can occur if operational loading beyond the elastic shakedown limit boundary. 


\section{Conclusions}

Cyclic plasticity of the ninety-degree back-to-back pipe bend structure subjected to cyclic thermomechanical loading are investigated by means of the LMM. With the observed results, following conclusions and remarks are made:

- With thermal load effects, the pipe bend structure under cyclic thermal load shows almost the same reverse plasticity limit as the structure subjected to cyclic out-of-plane bending. Therefore, the thermal stress effects require serious consideration of the integrity assessment of the pipe bends structure. Moreover, this study demonstrates that geometry changes such as variations of $r / t \&$ $R / r$ ratios do not affect reverse plasticity limit of the pipe bends under the cyclic thermal load, whereas they have significant influences on the reverse plasticity limit under the cyclic bending moments. Utilising the effect of temperature dependent material properties, this research presents more practical structural response against the complex thermo-mechanical loading.

- Without thermal load, the pipe bend structure under cyclic out-of-plane bending and constant internal pressure show shakedown limit boundary which is very adjacent to limit load boundary regardless the changes in geometry so that the shakedown limit boundary should replace the ratchet limit boundary. Therefore, allowable loading should be selected by maintaining enough margins below the elastic shakedown limit boundary. With decreasing of $r / t$ ratio, the pipe bends has large endurance capacity against cyclic out-of-plane bending than the constant pressure as $R / r$ ratio increases. However, the margins between the limit load and shakedown limit boundaries are very minimal. Therefore, conservative approaches in the design of the allowable loading should be made so that it can avoid unexpected plastic collapse. The horizontal pipe length shows very minor effects on the reverse plasticity limit but makes critical impacts on limit pressures.

- Comprehensive parametric studies provide understandings on cyclic plasticity behaviour of the pipe bend structure in associated with geometry effects of the pipe bends under different combinations of the loadings defined. In particular, the semi-empirical equations derived in Section 5.2.1 can be utilised to estimate shakedown limit boundary instead of carrying out complicated numerical analysis.

\section{Acknowledgement}

The authors gratefully acknowledge the supports from the National Natural Science Foundation of China (51828501), University of Strathclyde and East China University of Science and Technology during the course of this work. 


\section{References}

1. Karamanos, S.A., Mechanical Behavior of Steel Pipe Bends: An Overview. Journal of Pressure Vessel Technology, 2016. 138(4): p. 041203-041203-15.

2. $\quad \mathrm{Ni}$, J., et al., Effect of Pipe Bend Configuration on Guided Waves-Based Defects Detection: An Experimental Study. Journal of Pressure Vessel Technology, 2015. 138(2): p. 021203-0212039.

3. Vogelaar, B. and M. Golombok, Damage Detection Through Pipe Bends. Journal of Pressure Vessel Technology, 2017. 139(5): p. 051701-051701-7.

4. Chen, H., et al., On shakedown, ratchet and limit analyses of defective pipeline. Journal of Pressure Vessel Technology, 2012. 134(1): p. 011202.

5. Muscat, M. and D. Mackenzie, Elastic-shakedown analysis of axisymmetric nozzles. Journal of pressure vessel technology, 2003. 125(4): p. 365-370.

6. Urabe, Y., K. Takahashi, and H. Abe, Low Cycle Fatigue Evaluation of Pipe Bends With Local Wall Thinning Considering Multi-Axial Stress State. Journal of Pressure Vessel Technology, 2015. 137(4): p. 041404-041404-9.

7. Ure, J., H. Chen, and D. Tipping, Verification of the linear matching method for limit and shakedown analysis by comparison with experiments. Journal of Pressure Vessel Technology, 2015. 137(3): p. 031003.

8. Bree, J., Elastic-plastic behaviour of thin tubes subjected to internal pressure and intermittent high-heat fluxes with application to fast-nuclear-reactor fuel elements. The Journal of Strain Analysis for Engineering Design, 1967. 2(3): p. 226-238.

9. Seshadri, R., Inelastic evaluation of mechanical and structural components using the generalized local stress strain method of analysis. Nuclear Engineering and Design, 1995. 153(2-3): p. 287-303.

10. Dhalla, A. A simplified procedure to classify stresses for elevated temperature service. in ASME transactions, PVP division conference. 1987.

11. Chen, H. and A.R. Ponter, Shakedown and limit analyses for 3-D structures using the linear matching method. International Journal of Pressure Vessels and Piping, 2001. 78(6): p. 443451.

12. Chen, H. and A.R. Ponter, Linear Matching Method on the evaluation of plastic and creep behaviours for bodies subjected to cyclic thermal and mechanical loading. International Journal for Numerical Methods in Engineering, 2006. 68(1): p. 13-32.

13. Chen, H. and A.R. Ponter, A direct method on the evaluation of ratchet limit. Journal of Pressure Vessel Technology, 2010. 132(4): p. 041202.

14. Abdalla, H.F., Shakedown boundary determination of a $90^{\circ}$ back-to-back pipe bend subjected to steady internal pressures and cyclic in-plane bending moments. International Journal of Pressure Vessels and Piping, 2014. 116: p. 1-9.

15. Abdalla, H.F. Shakedown Boundary of a 90-Degree Back-to-Back Pipe Bend Subjected to Steady Internal Pressures and Cyclic Out-of-Plane Bending Moments. in ASME 2014 Pressure Vessels and Piping Conference. 2014. American Society of Mechanical Engineers.

16. Chen, H., et al., Shakedown and limit analysis of 90 pipe bends under internal pressure, cyclic in-plane bending and cyclic thermal loading. International Journal of Pressure Vessels and Piping, 2011. 88(5): p. 213-222.

17. Chen, X., B. Gao, and G. Chen, Ratcheting study of pressurized elbows subjected to reversed in-plane bending. Journal of Pressure Vessel Technology, 2006. 128(4): p. 525-532.

18. Cho, N.-K. and H. Chen, Shakedown, ratchet, and limit analyses of $90^{\circ}$ back-to-back pipe bends under cyclic in-plane opening bending and steady internal pressure. European Journal of Mechanics-A/Solids, 2017. 
19. Oh, C.-S., Y.-J. Kim, and C.-Y. Park, Shakedown limit loads for elbows under internal pressure and cyclic in-plane bending. International Journal of Pressure Vessels and Piping, 2008. 85(6): p. 394-405.

20. Chen, H. and A.R. Ponter, A method for the evaluation of a ratchet limit and the amplitude of plastic strain for bodies subjected to cyclic loading. European Journal of Mechanics-A/Solids, 2001. 20(4): p. 555-571.

21. Ponter, A.R. and H. Chen, A minimum theorem for cyclic load in excess of shakedown, with application to the evaluation of a ratchet limit. European Journal of Mechanics-A/Solids, 2001. 20(4): p. 539-553.

22. Melan, E., Theorie statisch unbestimmter Systeme aus ideal-plastischem Baustoff. 1936: Hölder-Pichler-Tempsky in Komm. 